\title{
Os perímetros irrigados como estratégia geopolítica para o desenvolvimento do semiárido e suas implicações à saúde, ao trabalho e ao ambiente
}

\author{
Irrigated perimeters as a geopolitical strategy \\ for the development of the semi-arid region \\ and its implications for health, labor and the environment
}

\author{
Andrezza Graziella Veríssimo Pontes ${ }^{1}$ \\ Diego Gadelha ${ }^{2}$ \\ Bernadete Maria Coêlho Freitas ${ }^{3}$ \\ Raquel Maria Rigotto ${ }^{1}$ \\ Marcelo José Monteiro Ferreira ${ }^{4}$
}

${ }^{1}$ Grupo de Pesquisa Marcos Teóricos Metodológicos Reorientadores da Educação e do Trabalho em Saúde, Faculdade de Enfermagem Universidade do Estado do Rio Grande do Norte, Núcleo Trabalho, Meio Ambiente e Saúde (Tramas), UFC.

R. Dionísio Filgueira 383, Centro. 59.610-090

Mossoró RN

andrezzagazi@hotmail.com

${ }^{2}$ Instituto Federal de

Educação, Ciência e

Tecnologia de Limoeiro do

Norte.

${ }^{3}$ Faculdade de Filosofia

Dom Aureliano Matos.

${ }^{4}$ Faculdade de Medicina,

Universidade do Estado do

Ceará, Núcleo TRAMAS,

UFC.

\begin{abstract}
An analysis was made of irrigated perimeters as a geopolitical strategy for expanding Brazilian agricultural frontiers and the "development" of the northeastern semi-arid region with respect to social determinants in health in rural communities. Research was conducted in the Chapada do Apodi in the states of Ceará and Rio Grande do Norte between 2007 and 2011. Various research techniques and tools were adopted, such as research-action, ethnographic studies, questionnaires and laboratory exams, water contamination analyses, social cartography and focal groups. In the context of agribusiness expansion, it was revealed that public policies of irrigation have had consequences for health, labor and the environment with the implementation of the Jaguaribe-Apodi Irrigated Perimeter in Ceará. The social and environmental conflict and resistance in the phase prior to the installation of the Santa Cruz do Apodi Irrigated Perimeter in Rio Grande do Norte was significant as it had consequences for the health-disease process on rural communities. It is important for the evaluation of public irrigation policies to consider the impacts of the perimeters on the lifestyle, labor, health and the environment of the affected territories.

Key words Health of the rural population, Health-disease process, Agricultural Irrigation, Occupational health, Environmental health, Public policies
\end{abstract}

Resumo Objetiva-se analisar os perímetros irrigados enquanto estratégia geopolitica para a expansão da fronteira agrícola brasileira e o "desenvolvimento" do semiárido nordestino, em sua relação com os determinantes sociais da saúde em comunidades camponesas. Trata-se de pesquisa realizada na Chapada do Apodi, nos estados do Ceará e Rio Grande do Norte, entre 2007 e 2011. Adotaram-se variados desenhos, técnicas e instrumentos de pesquisa, como pesquisa-ação, estudo etnográfico, questionário e exames laboratoriais, análise de contaminação de águas, cartografia social e grupo focal. Identificou-se que, na conjuntura da expansão do agronegócio, as políticas públicas de irrigação trouxeram consequências para a saúde, o trabalho e o ambiente, com a implantação do Perímetro Irrigado Jaguaribe-Apodi, no Ceará. São expressivos o contexto de conflito socioambiental e a resistência na fase prévia à instalação do Perímetro Irrigado Santa Cruz do Apodi no Rio Grande do Norte, o que traz consequências para o processo saúde-doença em comunidades camponesas. É importante a avaliação da política pública de irrigação considerar os impactos dos perímetros sobre o modo de vida, o trabalho, a saúde e o ambiente nesses territórios atingidos.

Palavras-chave Saúde da população rural, Processo saúde-doença, Irrigação agrícola, Saúde do trabalhador, Saúde ambiental, Políticas públicas 


\section{Introdução}

O debate acerca dos Determinantes Sociais de Saúde (DSS) foi, recentemente, retomado e impulsionado como tema de saúde pública de relevância mundial quando a Organização Mundial de Saúde (OMS) compôs, em março de 2005, a Comissão para os Determinantes Sociais da Saúde como parte de um movimento global de redução das desigualdades sociais em saúde ${ }^{1}$.

Embora se observe certo consenso sobre a importância dos DSS na situação de saúde, o embate teórico o substitui quando se trata de estabelecer as mediações entre os elementos mais gerais de ordem de natureza social, econômica, política e a situação de saúde de pessoas e grupos populacionais, considerando que a relação de determinação não é uma simples relação direta de causa e efeito ${ }^{2}$.

Este estudo fundamenta-se na tese da determinação social do processo saúde/doença ${ }^{3,4}$, a qual exerceu, particularmente, no Brasil, grande influência na conformação das bases teóricas do movimento da reforma sanitária brasileira, do Sistema Único de Saúde (SUS) e da Saúde Coletiva. A partir dessas discussões, a Lei 8.080/90 traz que a saúde tem como "determinantes e condicionantes, entre outros, a alimentação, a moradia, o saneamento básico, o meio ambiente, o trabalho, a renda, a educação, o transporte, o lazer e o acesso aos bens e serviços essenciais" ". A Constituição Federal de 1988 reconhece que o direito à saúde deve ser garantido mediante políticas econômicas e sociais ${ }^{6}$. Entende-se, aqui, que o modelo de desenvolvimento adotado por uma sociedade possui uma relação dialética com o processo saúde-doença individual/coletivo.

O modelo de desenvolvimento capitalista, avançando na globalização com a reestruturação produtiva e o neoliberalismo, tem penetrado não só o espaço da cidade, mas também do campo, modificando profundamente a relação sociedade-natureza e os modos de vida de comunidades camponesas.

O contexto da sociedade contemporânea no qual se inserem os eixos da Rio + 20 sobre "economia verde para a eliminação da miséria global e governança para a sustentabilidade do planeta" é caracterizado por um sistema globalizado em que aos países periféricos é destinada a produção de commodities com grande impacto ambiental e efeitos sobre a especulação do preço da terra; assassinatos de lideranças locais pelos latifundiários; monocultura agrícola, com uso intensivo de agrotóxicos e fertilizantes químicos e deslocamento de populações para "obras do desenvolvimento"'.

As políticas agrícolas no semiárido brasileiro, desde os anos 1960, vêm acompanhadas da implantação dos perímetros irrigados como estratégia geopolítica de expansão seletiva da fronteira agrícola ${ }^{8}$, na perspectiva da indução do desenvolvimento. Os perímetros irrigados são áreas delimitadas pelo Estado para implantação de projetos públicos de agricultura irrigada que, em geral, possuem significativo potencial agricultável, caracterizado pelos solos férteis, presença hídrica, clima favorável e abundante força de trabalho. Estes elementos conjugados às infraestruturas implementadas (canais, piscinas etc.) favorecem ampla produtividade agrícola. Tal estratégia é, agora, retomada pelo governo com grande ênfase e, certamente, vem ao encontro deste capital transnacional que aqui se instala para produzir commodities agrícolas, a partir de terra, água e mão de obra, facilidades de infraestrutura e de financiamento, além de condições políticas e institucionais favoráveis.

Bursztyn $^{9}$ e Diniz ${ }^{10}$, ao analisarem os resultados da política de irrigação, projetada pela Superintendência do Desenvolvimento do Nordeste (SUDENE) e executada pelo DNOCS, destacam que os perímetros públicos contribuíram para uma dupla desterritorialização dos camponeses. Primeiro, pelo fato de parte dos desapropriados não receberem lotes e serem expulsos de suas áreas; e, segundo, por conta da imposição do modelo de produção aos agricultores familiares, com base no paradigma da revolução verde, modelo este que, atualmente, é protagonizado pelo agronegócio. Este paradigma caracteriza-se pelo uso de insumos mecânicos e químicos, sobretudo os agrotóxicos, pela inserção da irrigação e pela imposição de culturas agrícolas previamente selecionadas de acordo com a rentabilidade do mercado, desconsiderando os saberes camponeses historicamente construídos.

Nesse sentido, é importante avaliar as implicações dessa política de irrigação do semiárido para a vida e a saúde nos territórios em que se insere. Este artigo objetiva analisar os perímetros irrigados enquanto estratégia geopolítica para a expansão da fronteira agrícola brasileira e "desenvolvimento" do semiárido nordestino, em sua relação com os determinantes sociais da saúde, em comunidades camponesas. A análise será conduzida a partir de dois estudos de caso no território da Chapada do Apodi: um em sua porção cearense, onde a irrigação foi implantada há duas décadas, e outro no Rio Grande do Norte, 
onde as comunidades aguardam a implantação de mais um perímetro irrigado (PI).

\section{Metodologia}

Este artigo é um desdobramento de duas pesquisas realizadas na Chapada do Apodi: "Estudo epidemiológico da população da região do Baixo Jaguaribe exposta à contaminação ambiental em área de uso de agrotóxicos", apoiada pelo Conselho Nacional de Desenvolvimento Científico e Tecnológico (CNPq) através de Edital, realizada no período de 2007 a 2011 nas cidades de Limoeiro, Russas e Quixeré, no estado do Ceará; e "As relações entre produção-trabalhoambiente-saúde: articulando a academia, o SUS e os movimentos sociais a partir de território camponês em conflito socioambiental", desenvolvida na cidade de Apodi, no estado do Rio Grande do Norte.

Para Bourdieu" "o método só funciona se conseguir inscrever-se nos mecanismos de um universo social". Assim, a complexidade dos objetos de investigação em sua interlocução com a dinâmica dos territórios exigiu a adoção de metodologias capazes de dialogar com as diferentes dimensões do problema.

Neste sentido, o delineamento utilizado pelas pesquisas supracitadas constituiu-se de uma triangulação metodológica agrupando aportes epistêmicos tanto do âmbito das ciências sociais e humanas como das ciências naturais, integrando-os em um contexto sócio-histórico ${ }^{12}$. Dessa forma, tornou-se possível a conjugação dos seguintes métodos e técnicas de pesquisa: aplicação de questionários e exames clínicos 540 trabalhadores em uma amostra estratificada; análises clínicas e imunogenéticas; análise de resíduos de agrotóxicos em águas subterrâneas e para consumo humano; caracterização socioambiental da área; acompanhamento da pulverização aérea, mapeamento das vulnerabilidades socioambientais junto às comunidades; estudo dos processos de produção; etnografia e pesquisa-ação ${ }^{13}$.

Já na pesquisa-ação da porção potiguar da Chapada do Apodi, realizada em 2011, encontros de discussão, entrevistas semiestruturadas, estudos de territorialização em saúde e estudos de processo de trabalho foram desenvolvidos junto com um grupo de pesquisa constituído por agentes comunitários de saúde de Equipe de Saúde da Família de Apodi (RN), Centro de Referência em Saúde do Trabalhador (CEREST), comunidades camponesas, professor universitário e movimentos sociais, como Comissão Pastoral da Terra e Sindicato dos Trabalhadores e Trabalhadoras Rurais de Apodi (RN).

Em acordo com a Resolução 196/96 ${ }^{14}$ do Conselho Nacional de Saúde, foram submetidas à avaliação e crivo dos Comitês de Ética na Pesquisa (CEP) da Universidade Federal do Ceará e da Escola de Saúde Pública do Ceará.

\section{Resultados e discussão}

\section{As políticas hidroagrícolas: estratégia para o semiárido nordestino}

O semiárido brasileiro concentra aproximadamente 20,8 milhões de pessoas que, historicamente, convivem com políticas públicas alicerçadas no discurso de que os problemas socioeconômicos regionais decorrem da combinação de processos naturais, com destaque para o fenômeno da seca.

Cabe destacar o papel da política de irrigação, impulsionada no final da década de 1960, como vetor de reestruturação do espaço agrário nordestino, por intermédio da implantação dos perímetros públicos de irrigação.

A irrigação pública implantada pelo Governo Federal em todo o Nordeste tinha, principalmente, os seguintes objetivos: introduzir um novo modelo de produção agrário/agrícola nessa região, via modernização da agricultura e incentivo a culturas agrícolas de maior rentabilidade, com destaque para a fruticultura irrigada; e minimizar os conflitos agrários e desviar o debate da reforma agrária para os projetos de colonização, por meio da seleção de irrigantes para ocupar os lotes dos perímetros públicos ${ }^{9,10}$.

Com base nos dados disponibilizados pelo Departamento Nacional de Obras contra as Secas (DNOCS), entre 1968 e 1992, foram construídos pelo Governo Federal 35 perímetros públicos irrigados na região semiárida nordestina, com destaque para o Ceará, onde foram instalados $40 \%$ de todos os perímetros. Analisando a Tabela 1 é possível identificar três períodos de construção: $80 \%$ dos perímetros iniciaram sua instalação no período de 1968-1979; 17\% no segundo período, de 1980-1989; e apenas 1 (um) perímetro, o Tabuleiros de Russas, no Ceará, teve sua construção iniciada na década de 1990.

A estrutura fundiária dos perímetros irrigados está distribuída em 4 classes de ocupantes: pequenos produtores, médios produtores, profissionais das Ciências Agrárias (técnicos de nível 
Tabela 1. Distribuição dos perímetros irrigados (DNOCS) no semiárido.

\begin{tabular}{lcccc}
\hline & & \multicolumn{3}{c}{ Período de construção } \\
\cline { 3 - 5 } \multicolumn{1}{c}{ Estados } & $\mathbf{N}^{\text {o }}$ de perímetros & $\mathbf{1 9 6 8 - 1 9 7 9}$ & $\mathbf{1 9 8 0 - 1 9 8 9}$ & $\mathbf{1 9 9 0 - 1 9 9 2}$ \\
\hline Bahia & 3 & 3 & 0 & 0 \\
Ceará & 14 & 10 & 3 & 1 \\
Paraíba & 3 & 3 & 0 & 0 \\
Pernambuco & 4 & 4 & 0 & 0 \\
Piauí & 6 & 4 & 2 & 0 \\
Rio Grande do Norte & 5 & 4 & 1 & 0 \\
Total & 35 & 28 & 6 & 1 \\
\hline
\end{tabular}

superior) e empresas. Os lotes distribuídos variam de 2 a 8 hectares para os pequenos produtores e chegam até 300 hectares para a categoria das empresas.

Freitas ${ }^{15}$, em sua análise, qualifica a concepção dos perímetros irrigados em dois momentos. Na primeira fase, 1968-1979, a política de irrigação tinha como prioridade a distribuição de lotes para a categoria dos pequenos produtores. Após a década 1990, há uma reorientação da ação estatal, com início da privatização do território e o domínio da estrutura fundiária por parte das empresas. Comparando o número de irrigantes por categoria (pequeno produtor versus empresa) e a área ocupada, é notória a dominação do território por parte das empresas. No projeto Tabuleiros de Russas (CE), são 622 irrigantes: 499 são pequenos produtores e 78 são empresas. Os pequenos irrigantes representam $88,22 \%$ do universo total e ocupam $37,78 \%$ da área total de 10.564 ha. Já as empresas, que representam $12,54 \%$ do total, concentram $47,65 \%$ da área.

No projeto Baixo Assu (RN), são 197 irrigantes: 156 pequenos produtores $(25,73 \%)$ e 25 empresas $(7,88 \%)$. Os pequenos irrigantes concentram $25,73 \%$ da área total contra $70,15 \%$ da área destinada às empresas.

A partir de 2011, no contexto do Programa de Aceleração do Crescimento (PAC) 2, configura-se "uma nova política nacional de irrigação", de acordo com o Ministro de Integração ${ }^{16}$. Criase a Secretaria Nacional de Irrigação, com o objetivo de configurar um sistema de gestão para a agricultura irrigada, apoiando sobremaneira a iniciativa privada e promovendo a irrigação como instrumento de eficiência na produção agrícola para erradicar a pobreza com a geração de emprego e renda ${ }^{17}$.

O Plano Plurianual de 2012-2015 prevê recursos da ordem de 6,9 bilhões de reais para a expansão dos perímetros e tem, entre suas metas, concluir as fronteiras já existentes para ampliar a área irrigada em 193.137 ha e instalar novos perímetros em 200.000 ha. No primeiro caso, estaria o Perímetro Tabuleiro de Russas, no Ceará, e, no segundo, os PI Mendubim e Santa Cruz de Apodi, no Rio Grande do Norte, este último também analisado neste artigo.

Outra meta importante para a modernização da nova política é a ampliação da atual área irrigada pelo setor privado em 100\% nos próximos quatro anos, substituindo a gerência estatal. Essas decisões políticas alicerçam-se na avaliação positiva da estratégia de irrigação.

Segundo o ministro, a agricultura irrigada é a atividade econômica que trouxe os melhores resultados para o País, superando setores como a indústria automotiva e a naval. A irrigação emprega 550 mil trabalhadores e gera $\mathrm{R} \$ 500$ milhões em impostos por ano ${ }^{17}$.

Essa avaliação não leva em conta uma teia complexa de impactos dos perímetros irrigados sobre a vida e a saúde das populações desses territórios. Os estudos de caso a seguir contribuem para a visualização dessa dimensão ocultada.

\section{As implicações do agronegócio/agrotóxicos para a saúde, o trabalho e o ambiente na chapada do Apodi, no Ceará}

O processo de desterritorialização em curso na porção cearense da Chapada do Apodi tem como momento marcante a implementação de grandes empresas transnacionais e nacionais de fruticultura para exportação, a partir dos anos 2000. Entre os muitos atrativos oferecidos pelo governo estadual, está a disponibilidade de água para irrigação dos cultivos, a partir do Perímetro Irrigado Jaguaribe-Apodi e, ainda, das águas do Aquífero Jandaíra, que também perpassa o subsolo potiguar. 
A expansão do agronegócio na região caracteriza-se por transformações provocadas nos territórios as quais modificam as relações e as condições de trabalho, o ambiente e a saúde das populações camponesas. A contaminação ambiental e humana pelo uso intensivo de agrotóxicos nos processos produtivos do agronegócio, com consequências danosas para a saúde da população, sejam moradores ou trabalhadores dessas empresas, bem como para o ambiente, marca o contexto da modernização agrícola nesse local. Esta tem ocasionado também profundas modificações no modo de vida das comunidades, desde o aumento de violência, inserção de drogas junto a escolares, prostituição e migração.

A moradia e o acesso à terra, importantes determinantes sociais da saúde para o camponês, são significativamente alterados nesse processo: comunidades inteiras são extintas, muitas vezes, com violência, como aconteceu com a comunidade denominada de KM 69, em que um dos artifícios empregados foi espalhar enxofre na direção dos ventos para as casas, obrigando as famílias a deixarem suas terras. Assim, pequenos agricultores migram para a periferia das cidades e se transformam em empregados do agronegócio ${ }^{18}$.

Com relação ao ambiente e à segurança alimentar, estudos identificaram a contaminação das águas subterrâneas na região. A Companhia de Gestão dos Recursos Hídricos ${ }^{19}$ analisou a presença de resíduos de agrotóxicos em dez amostras de água de poços na Chapada do Apodi-CE e estes foram identificados em seis amostras. A pesquisa analisou 23 amostras de águas superficiais e para consumo humano, provenientes dos canais que abastecem as comunidades, das caixas d'água e de poços profundos, e foi constatada a presença de princípios ativos em todas elas ${ }^{20}$.

Essa contaminação ambiental e humana por agrotóxicos é agravada pela prática de pulverizações aéreas na Chapada do Apodi (CE), que ameaçam a saúde pública devido à proximidade entre as áreas de cultivo e as comunidades; à elevada toxicidade da classificação dos agrotóxicos fungicidas utilizados, em sua maioria, extremamente ou muito tóxicos, além de altamente persistentes no ambiente; e à estimativa do volume de calda tóxica aplicado no total de 2.950 ha de cultivo de banana, que chegaria a 442.500 litros lançados por ano, nos últimos dez anos.

$\mathrm{O}$ agronegócio também trouxe consequências para o trabalho, um dos principais determinantes sociais de saúde. Os camponeses, expropriados de suas terras por conta da pressão exer- cida pelos latifundiários, veem-se diante da alternativa infernal de aceitar o emprego oferecido na grande empresa, passando de trabalhadores autônomos para assalariados do agronegócio. Evidencia-se ainda a sazonalidade nos vínculos trabalhistas, com contratos que duram somente seis meses, correspondentes ao período da plantação até a colheita dos frutos, momento em que a empresa necessita de mais mão de obra. Ao final desse período, grande parte dos trabalhadores é demitida, configurando-se assim uma força de trabalho descartável ${ }^{21}$.

Com o modelo de produção adotado no agronegócio, há intensa exposição ocupacional a agrotóxicos e fertilizantes. A pesquisa realizada com 540 trabalhadores, dos quais 341 do agronegócio, 156 agricultores familiares camponeses e 43 trabalhadores dos assentamentos e comunidades agroecológicas, identificou um quadro de grave problema de saúde pública, pois mais de $97 \%$ dos trabalhadores dos dois primeiros segmentos estão expostos a agrotóxicos ${ }^{22}$.

Entre os trabalhadores examinados, 46,6\% queixaram-se de problemas de saúde e os relacionaram aos agrotóxicos, e 43,3\% referiram quadros que podem ser considerados como intoxicação aguda em algum momento da vida. Entre os problemas atuais de saúde, destaca-se a alta prevalência de relatos de problemas neurológi$\cos (78,45 \%)$. Transtornos mentais comuns, avaliados por meio do Self Report Questionnaire (SRQ20), foram encontrados em 24,3\% dos trabalhadores do agronegócio e da agricultura familiar, o que pode ser compreendido como resultante, além da exposição aos agrotóxicos, da relação com todo o contexto de transformação no modo de vida do camponês empregado ${ }^{22}$.

Chama atenção ainda a repercussão dessa exposição a agrotóxicos sobre a função hepática dos trabalhadores: os indicadores apareceram em 53\% da amostra de trabalhadores do agronegócio do abacaxi na região ${ }^{21}$. Merece destaque a ocorrência de óbito de trabalhador de 29 anos, do monocultivo do abacaxi, por hepatopatia crônica tóxica ${ }^{23}$.

$\mathrm{Na}$ investigação sobre casos de câncer, foi averiguada incidência de neoplasias em trabalhadores rurais do sexo masculino através de dados secundários, em hospital de referência no Estado do Ceará, comparando-se casos entre agricultores e não agricultores, em série histórica de 2000 a 2006 e calculando-se a Razão Proporcional de Incidência de Câncer (PCIR), ajustada por idade. $\mathrm{O}$ resultado apresentou risco de câncer maior para os agricultores em 15 das 23 localizações 
anatômicas estudadas, como pênis $(6,44)$, leucemias $(6,35)$ e testículos $(5,77)^{24}$.

Os resultados da pesquisa evidenciam o contexto de vulnerabilidade das comunidades camponesas da Chapada do Apodi cearense pela expansão do agronegócio. Configurando forte conflito ambiental, emerge a resistência de movimentos sociais da região e comunidades camponesas, em que a violência é outro risco, exemplificado no assassinato de Zé Maria do Tomé, uma liderança comunitária que denunciava a expropriação das terras e a contaminação pelos agrotóxicos, especialmente, através da pulverização aérea.

Em síntese, o PI Jaguaribe-Apodi traz implicações para o trabalho, o ambiente e a saúde, tais como: a concentração de terras e os deslocamentos compulsórios da população; a violência; o comprometimento da segurança alimentar; mudanças nas práticas sociais e laços de vida comunitária; imposição de novos hábitos culturais; mudanças na dinâmica de cidades vizinhas, com a formação de "favelas" rurais; uso intensivo de novas tecnologias de mecanização e de insumos (fertilizantes e agrotóxicos); relações e condições de trabalho precarizadas com baixa remuneração, descumprimento da legislação trabalhista, intensificação do trabalho, exposição a situações de risco à saúde; redução da biodiversidade e dos serviços ambientais, degradação do solo pela monocultura e risco de desertificação; elevado consumo de água; contaminação do ar e de águas superficiais e subterrâneas por fertilizantes e agrotóxicos; exposição das comunidades do entorno das fazendas à contaminação pelos agrotóxicos utilizados de forma intensiva ${ }^{25}$.

Registre-se, entretanto, que esses impactos não vêm sendo monitorados ou reconhecidos pelas instâncias responsáveis no Estado; ocultar os agravos à saúde, a precarização do trabalho e a contaminação ambiental fazem parte da estratégia de sustentação desse modelo de desenvolvimento.

\section{O perímetro irrigado Santa Cruz do Apodi e sua relação com a saúde e o ambiente: conflito socioambiental e resistência na chapada do Apodi, no Rio Grande do Norte}

Apodi é um município do Rio Grande do Norte situado na microrregião Chapada do Apodi. Possui uma população de 34.777 habitantes, dos quais 17.545 estão na zona urbana e 17.232 na zona rural, uma área territorial de 1.602,47 $\mathrm{km}^{2}$ e a caatinga como bioma ${ }^{26}$.

As comunidades camponesas da Chapada do Apodi (RN) destacam-se por desenvolver, há várias décadas, projetos de base agroecológica, como a apicultura, caprinocultura e a agricultura familiar camponesa, com apoio de movimentos sociais e entidades sindicais, pastorais e ambientalistas, além de setores da universidade.

Esse processo tem permitido a construção de um modo de vida e trabalho da agricultura familiar camponesa de Apodi (RN) com valores, costumes e culturas distintos da lógica capitalista. Os discursos colhidos nas comunidades revelam o sentimento de orgulho e de satisfação dos que se sentem sujeitos desse processo. A satisfação em realizar um trabalho que alimenta a população em geral, seja do campo ou da cidade; $o$ costume de acordar cedo; o vínculo do homem com a natureza e com os animais; a preocupação com as gerações futuras; a perpetuação da cultura de pais para filhos; as atividades de lazer, como sentar na calçada, jogar futebol, ir à igreja, conversar com os vizinhos; a tranquilidade; o vínculo e a amizade entre as pessoas são ressaltados por esses moradores como potencialidades dessa forma de viver e trabalhar que constituem processos protetores da saúde. Entretanto essa rica experiência, exemplar de uma maneira mais justa e sustentável de convivência com o semiárido, está ameaçada pelo Projeto de Irrigação Santa Cruz do Apodi, proposto pelo DNOCS.

Na chapada, a gente sabe que tem várias pessoas que vivem daquilo, de plantação, de várias coisas: milho, feijão, algodão, sorgo e, principalmente, da cultura do mel. Nós somos um dos maiores produtores de mel. Aí, se vier esse projeto e acabar com tudo, como é que essas famílias vão sobreviver? Quem já tem, a gente quer melhorar, a gente não quer mexer no que já tem. Então a gente quer que todo mundo viva bem e conviva na terra que está para se sustentar nela, e não destruir tudo que a gente tem, a gente tem água boa, tem solo fértil (ACS 4).

É que, em 10 de junho de 2011, a presidência da república decretou a desapropriação de área de terra de 13.855,13 hectares, onde vivem essas comunidades, para dar lugar à instalação do Perímetro de Agricultura Irrigada de Santa Cruz Apodi, que se estende pelos municípios de Apodi e Felipe Guerra, no RN. Serão investidos R \$ 209.208.693,30 nesse projeto de irrigação ${ }^{27}$, que está em fase de ação preparatória, com licença ambiental expedida em 2010. De acordo com a nova política de irrigação do governo federal, fica clara a destinação dessas terras à expansão do agronegócio.

As comunidades camponesas e os movimentos sociais da região resistem fortemente e, tam- 
bém lá, configura-se um conflito ambiental de caráter territorial e distributivo ${ }^{28}$. Em seu cerne, está a disputa pelo modelo de desenvolvimento rural que se quer para o município, no qual o movimento social defende alternativas agroecológicas. A luta contra o agronegócio tem como propulsores a questão dos agrotóxicos e a defesa do acesso igualitário à água, para o que contribuiu o conhecimento das consequências dessa modernização no lado cearense da chapada.

A primeira questão é: 'Por que contestar o projeto de irrigação da Chapada do Apodi aqui, no municipio de Apodi? Geralmente, o pessoal diz que a gente é que tem sido até antiquado nos nossos dizeres, porque 'ora, não querer o desenvolvimento para o nosso município?.' Mas que desenvolvimento é esse que traz doenças, que traz mazelas para quem está lá no campo? A Chapada do Apodi da parte que compreende o Ceará está sendo alvo de inumeros problemas sociais e ambientais trazidos pelo agronegócio. E, aqui, a gente tem como anteceder esses fatos. Então, não se pode aceitar um projeto de irrigação baseado numa ótica de desenvolvimento totalmente contraditória para a realidade local. São essas experiências que o DNOCS acumula no que diz respeito à execução de projetos de irrigação no Nordeste. Então, é preciso a gente ver que desenvolvimento é esse, para quê. Quando vêm empresas transnacionais, com a tendência de a gente produzir aqui e levar lá para o exterior, então, para quem vai ficar esse desenvolvimento? Será que é desenvolvimento? O que interessa para o capitalismo e o agronegócio são os números, a balança favorável para tirar o país de uma crise, que a gente não tem nada a ver com isso. A gente tem que viver nossa vida bem e com saúde. Nós que somos agricultores, a gente quer é viver com saúde, lazer, em paz, nas nossas pequenas propriedades. No município de Apodi, a gente tem a questão do manejo da caatinga, a apicultura, que é muito forte, a caprinocultura, a questão das hortaliças orgânicas, a agricultura de sequeiro, a questão da produção de polpas de fruta, que também existe, e os quintais produtivos, que é a questão de você ter, nos seus quintais, a galinha, um canteirozinho, uma coisa toda que vai vivendo bem ali, com saúde e dignidade (Movimentos sociais 3 ).

Observa-se que as comunidades camponesas e os movimentos sociais da região estão sendo sujeitos de sua saúde. Enquanto o Estado induz à vulnerabilidade e à doença com a instalação do perímetro irrigado/agronegócio/agrotóxicos, os atores locais do território resistem. A resistência contribui para a prevenção, proteção e promoção à saúde, competências do SUS. Trata-se da contradição do Estado, o qual, enquanto SUS, tem o dever de garantir a saúde dessas comunidades, mas, ao mesmo tempo, como DNOCS, atua como um indutor do modelo de desenvolvimento pautado no agronegócio, que se constitui um determinante social de saúde nos territórios camponeses.

$\mathrm{Na}$ medida em que se firmam as contradições do modelo, a resistência ganha força para além dos contornos locais e se constitui uma rede de movimento social no Rio Grande do Norte, expandindo suas ações para o cenário nacional.

Depois que esse projeto começou a ganhar força lá em Apodi, também da mesma forma, o movimento também começou a ganhar força (Movimentos sociais 1 ).

Compreendendo que a garantia de seu modo de vida e a proteção de sua saúde estão articuladas, os movimentos e as comunidades arregaçam as mangas e promovem seminários sobre as Sementes Crioulas ou acerca dos impactos do agronegócio/agrotóxicos sobre a saúde, o trabalho e o meio ambiente; realizam Audiência com o Ministro da Integração, questionando as prioridades políticas da irrigação, fazem Atos Públicos, discutem o PI nas comunidades atingidas, articulam-se em redes estaduais e nacionais, como a reunida na Campanha Permanente Contra os Agrotóxicos e Pela Vida; e o movimento das mulheres elabora duas mil cartas, escritas à mão, à presidenta da república.

Embora a instalação do PI Santa Cruz não tenha se iniciado, o conflito já está em curso e já se percebem alguns impactos decorrentes, principalmente, da desapropriação, que provoca a desterritorialização das comunidades rurais camponesas, e da falta de informação da população, gerando para as pessoas atingidas incertezas, medo do futuro, entre outros ${ }^{29}$.

Os relatos dão conta de que o Estado, na figura do DNOCS, realiza a desapropriação por se tratar de um "interesse público", em um processo autoritário:

O DNOCS, a primeira coisa que ele fez na Chapada do Apodi foi chegar nas propriedades, entrando sem pedir licença e amedrontando o agricultor (Comunidade camponesa).

Lá, quando chegaram a primeira vez no assentamento, eles disseram que a gente ia sair das casas e entregar tudo, porque ia pegar 100\%. Só que a gente bateu o pé e disse que não existe esse direito de você comprar uma terra, você está pagando, é sua, e os outros chegarem e se instalarem lá dentro como se fossem donos. Então, quando a gente se 
mobilizou, teve até uma reunião aqui na igreja, a gente fez muita mobilização social, o pessoal do DNOCS veio aqui e, depois, voltaram lá, para uma reunião com a gente, puxaram o mapa, colocaram em cima da mesa e disseram o seguinte: 'não vai mais pegar o assentamento todo, vai pegar em torno de 40\%, e a gente bateu o martelo e disse que não vai pegar nada porque a gente não quer nada, não quer nada porque a gente trabalha a agricultura familiar. Então, vai acabar a agricultura familiar na Chapada do Apodi? (ACS 2).

A perda e/ou alteração do território como suporte da memória e da vida ocasiona um desenraizamento e um esfacelamento da identidade individual e coletiva dos sujeitos, e isso desemboca em processos de desterritorialização.

A nossa preocupação é o projeto em si, da maneira como está dito, tirar famílias, que o cara é produtor, aí vir para onde? Isso deixa a gente bastante preocupado. Para onde essa família vai se estão lá há mais de cem anos que moram? (Movimentos sociais 2).

Identifica-se que esse empreendimento provoca a expulsão forçada das comunidades camponesas, seja diretamente pela desapropriação, seja pela sedução à venda de suas terras. Aos que tentam resistir, a insegurança da compatibilidade da vizinhança entre agronegócio e agroecologia. Aos que se reacomodam na região, resta a perspectiva de serem funcionais ao capital ${ }^{30}$, tornando-se empregados assalariados do agronegócio.

$O$ agricultor familiar que ficar vai produzir o que a empresa diz, não é o que ele quer, não é criar as galinhas dele, não é a horta, cada um vai produzir cacau ligado à empresa, o que ele for produzir é a empresa que vai dizer a ele o que ele vai produzir. Isso deixou a gente bastante preocupado. De primeiro, aqui na nossa região, teve uma luta grande da agricultura camponesa e, hoje, ainda tem muitos produzindo sem usar veneno, sem usar agrotóxicos (Movimentos sociais 2).

A ameaça às formas tradicionais de reprodução social já vem sendo percebida pelas comunidades:

Porque, quando chegar, vai acabar com a apicultura, porque nós sabemos que as abelhas não vão sobreviver onde tem esse veneno, caprinocultura também, porque os caprinos vão comer de quê? Porque são matas nativas que a gente tem lá nos lotes e algumas leguminosas que as pessoas já fizeram na unidade demonstrativa para dar as quantidades, proteínas, essas coisas. E o agrotóxico vizinho vai acabar com tudo isso. A gente vai ficar só com o quê? Só com a casa e um pedaço de terra sem ter condições de trabalhar. Por quê? Porque você vai fazer orgânico, mas não vai ficar orgânico, porque o veneno está ali próximo, atingindo as plantas, os animais, alimentação, tudo, as águas, o solo que vai ficar improdutivo (ACS 1).

Também os impactos sobre o processo saúde-doença individual/coletivo já são observados: transtornos mentais, como ansiedade, depressão, estresse, em decorrência do medo do que vem pela frente, de como será a vida com esse projeto.

Esse projeto vai causar um impacto em tudo na vida dos agricultores da Chapada do Apodi, já está causando, porque tem muita gente aí que já perdeu o sossego, não tem mais sossego, não dorme, não se alimenta mais que preste (ACS 2).

Com base na experiência vivida em outros locais, é possível antecipar outros impactos sobre a saúde, relacionados, principalmente, à perda da soberania alimentar e ao uso intensivo de agrotóxicos no agronegócio, atingindo tanto os trabalhadores como as comunidades do entorno, além da população em geral, que consome o alimento contaminado, a exemplo do que acontece na Chapada do Apodi do lado cearense.

O pior de tudo é que foi colocado bem claro que esse projeto que vem para cá, os agricultores morrem mais cedo do que mesmo o pessoal da cidade. E isso é uma coisa preocupante para nós (Comunidade camponesa).

Amplas transformações territoriais repercutem de forma diversificada na saúde, como o comprometimento da biodiversidade e do acesso a recursos naturais, como a terra e a água; desagregação familiar e novos padrões de gênero; a atração de grandes contingentes de trabalhadores de outras localidades para o território, o que gera novas demandas de saneamento, moradia, educação, lazer, transporte. Associamse também a esses processos migratórios a violência, acidentes de trânsito, doenças sexualmente transmissíveis e AIDS, consumo de álcool e drogas ilícitas, doenças mentais e sofrimento psíquico, gravidez precoce, entre outros ${ }^{31}$.

\section{Considerações finais}

Os perímetros irrigados têm sido impostos aos territórios como estratégia política para o desenvolvimento do semiárido. Recentemente, uma nova política nacional de irrigação retoma esse caminho para impulsionar, com vultosos recursos públicos, uma considerável expansão das áreas irrigadas. Entretanto uma avaliação mais rigorosa e abrangente dos efeitos dessa política 
aponta para questões que se afastam em muito do discurso que a legitimaria - erradicação da pobreza, geração de emprego e renda.

O estudo dos desdobramentos do Perímetro Irrigado Jaguaribe-Apodi, na porção cearense da chapada, evidencia que o agronegócio promove diversos impactos negativos sobre a saúde, o trabalho e o ambiente. A investigação da região de Apodi (RN) mostra que as comunidades, garantido o acesso à terra, têm podido construir um modo de vida produtivo, considerado satisfatório por elas. Se há um desejo de melhorias, elas não são no sentido de sair da terra para dar lugar a um projeto de desenvolvimento conduzido pelo grande capital, em que terão, no máximo, uma inserção subordinada e precarizada.

A avaliação da política pública de irrigação deveria levar em conta os impactos dos perímetros sobre o modo de vida, o trabalho, a saúde e o ambiente nesses territórios atingidos, em vez de decidir por uma expansão com base nos aspectos econômicos "positivos".

Assim como a política de irrigação, também os documentos da Rio +20 vêm colocando como eixo a erradicação da pobreza. Ou se trata de erradicar os pobres, para melhor usurpar as riquezas dos territórios que ainda lhes restam?

Nesse contexto de vulnerabilização das comunidades camponesas pelo próprio Estado, mediando os interesses do capital transnacional, não há que se esperar que a política pública de saúde possa, isolada, garantir o direito constitucional à saúde, nem prevenir ou proteger a população dos riscos.

Por outro lado, essas mesmas comunidades têm indicações preciosas ao Estado, já testadas em suas práticas nos territórios, de como promover vida e saúde, com justiça e sustentabilidade: necessário enxergá-las e ouvi-las, para aprender a respeitá-las.

\section{Colaboradores}

AGV Pontes trabalhou na concepção, análise e interpretação dos dados, redação e aprovação da versão final; D Gadelha e BMC Freitas trabalharam na concepção, redação e aprovação da versão final; RM Rigotto trabalhou na concepção, na redação, na revisão crítica e na aprovação da versão final; e MJM Ferreira trabalhou na redação e aprovação da versão final.

\section{Referências}

1. Organização Mundial de Saúde (OMS). Comissão para os Determinantes Sociais da Saúde (CDSS). Redução das desigualdades no período de uma geração. Igualdade na saúde através da ação sobre os seus determinantes sociais. Relatório Final da Comissão para os Determinantes Sociais da Saúde. Lisboa: OMS; 2010.

2. Buss PM, Pelegrini Filho A. A saúde e seus determinantes sociais. Physis Rev Saude Coletiva 2007; 17(1):77-93

3. Breilh J. Epidemiologia: economia, política e saúde. Tradução Luiz Roberto de Oliveira. São Paulo: Unesp, Hucitec; 1991.

4. Laurell AC. A saúde-doença como processo social. Rev Latino-am Salud 1982; 2:7-25.

5. Brasil. Lei 8.080 de 19 de setembro de 1990. Dispõe sobre as condições para a promoção, proteção e recuperação da saúde, a organização e o funcionamento dos serviços correspondentes e dá outras providências. Diário Oficial da União 1990; 19 set.

6. Brasil. Constituição 1998: texto constitucional de 5 de outubro de 1998, com as alterações adotadas pelas Emendas Constitucionais de revisão n ${ }^{\circ} .1$ a $6 /$ 94. Brasília: Senado Federal; 2000.

7. Miranda AC. O dilema da Rio + 20. [Editorial]. Cien Saude Colet 2012; 17(2):284.

8. Becker BK, Egler CAG. Brasil: uma potência regional na economia-mundo. $4^{\text {a }}$ Edição. Rio de Janeiro: Bertrand Brasil; 2003. 
9. Bursztyn M. O poder dos donos: planejamento e clientelismo no Nordeste. Petrópolis: Vozes; 1985.

10. Diniz AS. A construção dos perímetros irrigados e a criação de novas territorialidades. In: Elias D, Sampaio JLF, organizadores. Modernização excludente. Fortaleza: Demócrito Rocha; 2002. p.37-60.

11. Bourdieu P. O poder simbólico. 14a Edição. Rio de Janeiro: Bertrand Brasil; 2010.

12. Breilh J. Epidemiologia Crítica: ciência emancipadora e interculturalidade. Rio de Janeiro: Editora Fiocruz; 2006.

13. Rigotto RM, Ellery AEL. Caminhos na produção do conhecimento: cuidados, incertezas e criação. In: Rigotto RM, organizador. Agrotóxicos, trabalho e saúde: vulnerabilidade e resistência no contexto da modernização agrícola no Baixo Jaguaribe/CE. Fortaleza: UFC; 2011. p. 71-110.

14. Brasil. Resolução no $196 / 96$, de 10 de outubro de 1996. Dispõe sobre as diretrizes e normas regulamentadoras de pesquisas envolvendo seres humanos. Diário Oficial da União 1996; 11 out.

15. Freitas BMC. Marcas da modernização da agricultura do Perímetro Irrigado Jaguaribe-Apodi: uma face da atual reestruturação socioespacial do Ceará [dissertação]. Fortaleza: Universidade Estadual do Ceará; 2010.

16. Júnior M. Governo Federal vai lançar o PAC da irrigação. [Internet]. 2011 [acessado 2012 mar 28]. Disponível em: http://diariodonordeste.globo.com/ materia.asp? codigo $=1053209$

17. Portal Brasil. Programa nacional de irrigação para o Semiárido será lançado em setembro. 2011. [página na Internet]. [acessado 2012 mar 28]. Disponível em: http://www.brasil.gov.br/noticias/arquivos/ 2011/07/28/programa-nacional-de-irrigacao-parao-semiarido-sera-lancado-em-setembro

18. Marinho AMCP. Contextos e contornos da modernização agrícola em municípios do Baixo Jaguaribe-CE: o espelho do (des) envolvimento e seus reflexos na saúde, trabalho e ambiente [tese]. São Paulo: Universidade de São Paulo; 2010.

19. Companhia de Gestão de Recursos Hídricos (COGERH). Plano de Gestão Participativa dos Aquíferos da Bacia Potiguar, Estado do Ceará. Fortaleza: COGERH; 2009.

20. Marinho AMCP, Carneiro FF, Almeida VE. Dimensão socioambiental em área de agronegócio: a complexa teia de riscos, incertezas e vulnerabilidades. In: Rigotto RM, organizador. Agrotóxicos, trabalho e saúde: vulnerabilidade e resistência no contexto da modernização agrícola no Baixo Jaguaribe/CE. Fortaleza: UFC; 2011. p.166-216.

21. Ferreira MJM, Marinho AMCP, Castro FS, Portela GO. O olhar dos trabalhadores: O "Progresso" e a Saúde. In: Rigotto RM, organizador. Agrotóxicos, trabalho e saúde: vulnerabilidade e resistência no contexto da modernização agrícola no Baixo Jaguaribe/CE. Fortaleza: UFC; 2011. p. 414-430.
22. Maciel RHM, Rigotto RM, Alves PA. Como está a saúde destes trabalhadores? In: Rigotto RM, organizador. Agrotóxicos, trabalho e saúde: vulnerabilidade e resistência no contexto da modernização agrícola no Baixo Jaguaribe/CE. Fortaleza: UFC; 2011. p.391-413.

23. Alexandre SF. Exposição a agrotóxicos e fertilizantes químicos: agravos à saúde dos trabalhadores no agronegócio do abacaxí em Limoeiro do Norte-CE [dissertação]. Fortaleza: Universidade Federal do Ceará; 2009.

24. Ellery AEL, Arregi MMU, Ritoggo RM. Incidência de câncer em agricultores em hospital de câncer no Ceará. In: Anais do XVIII Congresso Mundial de Epidemiologia e VII Congresso Brasileiro de Epidemiologia, 2008.

25. Rigotto RM, Teixeira ACA. Desenvolvimento e sustentabilidade socioambiental no campo, na cidade e na Floresta. In: Conferência Nacional de Saúde Ambiental. Brasília: Caderno de Textos; 2009.

26. Instituto Brasileiro de Geografia e Estatística (IBGE). Cidades. 2010. [documento na Internet]. [acessado 2011 nov 28]. Disponível em: http://www.ibge. gov.br/cidadesat/painel/painel.php?codmun $=240100$

27. Departamento Nacional de Obras Contra as Secas (DNOCS). Relatório de Impacto Ambiental (RIMA), referentes à implantação do Projeto de Irrigação Santa Cruz do Apodi, situado nos municípios de Apodi e Felipe Guerra, no Estado do Rio Grande do Norte. Fortaleza: Acquatool Consultoria; 2009.

28. Zhouri A, Laschefski K. Desenvolvimento e conflitos ambientais: um novo campo de investigação. In: Zhouri A, Laschefski K, organizadores. Desenvolvimento e conflitos ambientais. Belo Horizonte: UFMG; 2010. p. 11-31.

29. Scherer-Warren I. Movimentos sociais e participação. In: Sorrentino M, organizador. Ambientalismo e participação na contemporaneidade. São Paulo: EDU, FAPESP; 2001. p. 41-56.

30. Leroy JP. Amazônia: território do capital e territórios dos povos. In: Zhouri A, Laschefski K, organizadores. Desenvolvimento e conflitos ambientais. Belo Horizonte: UFMG; 2010. p. 92-113.

31. Rigotto RM. Inserção da saúde nos estudos de impacto ambiental: o caso de uma termelétrica a carvão mineral no Ceará. Cien Saude Colet 2009; 14(6):2049-2059.

Artigo apresentado em 15/03/2012

Aprovado em 26/04/2012

Versão final apresentada em 02/05/2012 